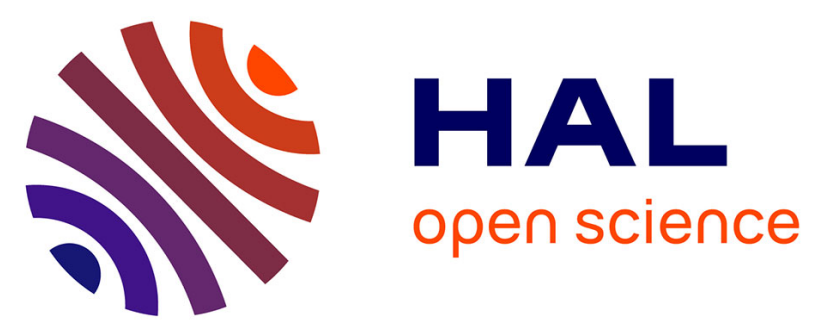

\title{
Double-dissociation between the mechanism leading to impulsivity and inattention in Attention Deficit Hyperactivity Disorder: A resting state functional connectivity study
}

Masafumi Sanefuji, Michael Craig, Valeria Parlatini, Mitul A. Mehta, Declan

G. Murphy, Marco Catani, Leonardo Cerliani, Michel Thiebaut de Schotten

\section{To cite this version:}

Masafumi Sanefuji, Michael Craig, Valeria Parlatini, Mitul A. Mehta, Declan G. Murphy, et al.. Double-dissociation between the mechanism leading to impulsivity and inattention in Attention Deficit Hyperactivity Disorder: A resting state functional connectivity study. Cortex, 2016, 10.1016/j.cortex.2016.06.005 . hal-01338850

\section{HAL Id: hal-01338850 https://hal.sorbonne-universite.fr/hal-01338850}

Submitted on 29 Jun 2016

HAL is a multi-disciplinary open access archive for the deposit and dissemination of scientific research documents, whether they are published or not. The documents may come from teaching and research institutions in France or abroad, or from public or private research centers.
L'archive ouverte pluridisciplinaire HAL, est destinée au dépôt et à la diffusion de documents scientifiques de niveau recherche, publiés ou non, émanant des établissements d'enseignement et de recherche français ou étrangers, des laboratoires publics ou privés. 


\section{Double-Dissociation between the mechanism leading to impulsivity and} inattention in Attention Deficit Hyperactivity Disorder.

Masafumi Sanefuji, $\mathrm{PhD}^{\mathrm{a}, \mathrm{b}}$, Michael Craig, $\mathrm{PhD}^{\mathrm{a}, \mathrm{b}, \mathrm{f} \uparrow}$, Valeria Parlatini, MD ${ }^{\mathrm{a}, \mathrm{b}}$, Mitul A Mehta, $\mathrm{PhD}^{\mathrm{c}}$, Declan G. Murphy, $\mathrm{PhD}^{\mathrm{a}, \mathrm{b}}$, Marco Catani, $\mathrm{PhD}^{\mathrm{a}-\mathrm{c}}$, Leonardo Cerliani, $\mathrm{PhD}^{\mathrm{d}, \mathrm{e}}$, Michel Thiebaut de Schotten, $\mathrm{PhD}^{\mathrm{a}-\mathrm{e}^{*}}$

${ }^{a}$ Natbrainlab, Department of Forensic and Neurodevelopmental Science (FANS), Institute of Psychiatry, King's College London, UK

${ }^{b}$ Sackler Institute of Translational Neurodevelopment, Department of FANS, Institute of Psychiatry, King's College London, UK

${ }^{c}$ Department of Neuroimaging, Institute of Psychiatry, King's College London, UK

${ }^{d}$ Inserm U1127, UPMC-Paris6, UMR_S 975, CNRS UMR 7225, Brain and Spine Institute, Groupe Hospitalier Pitié-Salpetrière, Paris, France

${ }^{e}$ Brain Connectivity and Behaviour Group, Brain and Spine Institute, Paris, France ${ }^{f}$ National Autism Unit, National Services Directorate, Bethlam Royal Hospital, SLAM NHS Foundation Trust, London, UK

"Joint first authors

* Corresponding author:

Michel Thiebaut de Schotten, PhD, CR2 CNRS

Natbrainlab, Brain and Spine Institute

La Salpêtrière, 47 Bd de l'Hôpital

75013 Paris, FRANCE

phone: +33950865060

michel.thiebaut@gmail.com

Word counts: abstract 277, article body 3436

Numbers of materials: 4 figures, 3 tables and 1 supplementary material. 
- ADHD showed an increased functional connectivity in the right hemisphere compared to controls.

- A single brain model for ADHD is insufficient

- Hyperactive-impulsive subtype was associated with increased connectivity in

cortico-striatal network

- Inattentive subtype was associated with increased connectivity in the right ventral attention network 


\begin{abstract}
Two core symptoms characterize Attention Deficit Hyperactivity Disorder (ADHD) subtypes: inattentiveness and hyperactivity-impulsivity. While previous brain imaging research investigated ADHD as if it was a homogenous condition, its two core symptoms may originate from different brain mechanisms. We, therefore, hypothesized that the functional connectivity of cortico-striatal and attentional networks would be different between ADHD subtypes. We studied 165 children (mean age 10.93 years; age range, 7-17 year old) diagnosed as having ADHD based on their revised Conner's rating scale score and 170 typical developing individuals (mean age 11.46 years; age range, 7-17 year old) using resting state functional fMRI. Groups were matched for age, IQ and head motion during the MRI acquisition. We fractionated the ADHD group into predominantly inattentive, hyperactive-impulsive and combined subtypes based on their revised Conner's rating scale score. We then analyzed differences in resting state functional connectivity of the cortico-striatal and attentional networks between these subtypes. We found a double dissociation of functional connectivity in the cortico-striatal and ventral attentional networks, reflecting the subtypes of the ADHD participants. Particularly, the hyperactive-impulsive subtype was associated with increased connectivity in cortico-striatal network, whereas the inattentive subtype was associated with increased connectivity in the right ventral attention network. Our study demonstrated for the first time a right lateralized, double dissociation between specific networks associated with hyperactivity-impulsivity and inattentiveness in ADHD children, providing a biological
\end{abstract}


basis for exploring symptom dimensions and revealing potential targets for more personalized treatments. 


\title{
INTRODUCTION
}

\author{
Attention deficit/hyperactivity disorder (ADHD) is a neurodevelopmental \\ condition affecting approximately $8 \%$ of school-aged children (Bloom et al. 2011) and \\ 4\% of adults (Kessler et al. 2006). Originally described in 1798 (Crichton 1798; reprinted \\ in Crichton 2008) ADHD patients 'incessantly withdrawn from one impression to \\ another' and 'excites such a degree of anger as borders on insanity' (for an historical \\ review see Lange et al. 2010). These two core symptoms are interpreted as inattention
} and hyperactivity-impulsivity in the DSM5 (American Psychiatric Association 2013) and can be of variable severity. Although these symptoms frequently come together, their expression can be unbalanced leading to the division of ADHD into three clinical subtypes: predominantly inattentive, predominantly hyperactive-impulsive, and combined (American Psychiatric Association 1994). Whether the brain mechanism leading to these subtypes is different remains to be clarified in order to enhance personalised treatment.

The efficacy of current drug treatments is predominantly mediated by their effects on the dopaminergic, and/or noradrenergic systems. They are effective in many patients, but approximately $1 / 3$ fail to respond - predominantly those with the 'inattentive' subtype (Spencer et al. 1995; Weiss et al. 2005; Hazell et al. 2011). This finding suggests that in addition to being clinically heterogeneous (Barkley et al. 2002; Biederman et al. 2006); ADHD subtypes may be modulated by different brain systems with a variable response to pharmacological treatments. 
There is increasing evidence that ADHD is associated with abnormalities in specific brain regions; and particularly dorsal anterior midcingulate cortex (daMCC), prefrontal cortex, parietal cortex, striatum, and cerebellum (see Bush 2011; Cortese et al. 2012 for review). The significance of these areas is that they are involved with attention, executive function, motor control, response inhibition, and working memory. However, rather than a mosaic of functionally specialized areas, the human mind is believed to emerge from the coordinated activity of distant but anatomically interconnected regions. Advances in brain imaging have enabled us to study anatomical and functional connectivity within these networks in vivo.

One of the most consistent findings from studies of anatomical connectivity, in children and adolescents with ADHD, is reduced fractional anisotropy (Hamilton et al. 2008; Makris et al. 2008; Luders et al. 2009; Konrad et al. 2010) of fronto-striatal tracts (within the cortico-striatal network) and fronto-parietal tracts (within the ventral and dorsal attention network). These findings have been supported by some (Dickstein et al. 2006; Rubia 2011; Cubillo et al. 2012) but not all studies of functional connectivity (Tian et al. 2006; Uddin et al. 2008).

Studies of functional connectivity have employed standard, task-activation, $f M R I$ (task-fMRI), or resting-state $f M R I$ (rs- $f M R I)$. A key advantage of rs- $f M R I$ is that 
participants are not required to focus on an explicit task. This is particularly beneficial in ADHD, where compliance and attention during scanning may be problematic, and confound interpretation of results. The underlying principle of rs-fMRI is that functional connectivity between brain regions can be successfully mapped by correlating spontaneous low-frequency $(<0.1 \mathrm{~Hz})$ fluctuations in blood oxygenation level dependent (BOLD) signal at rest (Fox and Raichle 2007). Previous rs- $f$ MRI studies of ADHD have reported both hypo- and hyper-activation of fronto-striatal, fronto-parietal and other networks (see Konrad et al. 2010 for review). Also, whole brain voxel-based analyses revealed decreased entropy (Sokunbi et al. 2013) and decreased amplitude of low-frequency fluctuation (Zang et al. 2007; An, Cao, Sui, et al. 2013) in the frontal and the occipital lobes. These inconsistencies are likely to be due to a combination of methodological factors, including the method of analysis employed, micro-movements (Fair et al. 2012), variability in the subtype diagnosis and the age range of subjects. The small size of clinical samples has also been a significant limitation of the majority of imaging studies of ADHD to date. An important consequence of this has been the scarcity of studies with the statistical power to analyse ADHD as a heterogeneous condition. Therefore there has been a need for larger studies, with sufficient power to fractionate $\mathrm{ADHD}$ into its clinical subtypes, and that permit a more comprehensive analysis of brain connectivity.

In the present study we accessed a recent, unrestricted public release, dataset of 
rs-fMRI images from 255 children and adolescents with ADHD (ages: 7-21 years old) ${ }^{\dagger}$. This has provided a valuable opportunity to analyse whether the clinical heterogeneity observed in ADHD is underpinned by differences at a functional brain network level. We focused our analyses on three resting state networks of interest, the dopaminergic circuit (i.e. cortico-striatal circuit Alexander et al. 1986; Nieuwenhuys et al. 2008) for its essential role in impulsivity (Buckholtz et al. 2010), and the dorsal and the ventral fronto-parietal networks (Fox et al. 2006) for their key role in attention (i.e. dorsal and ventral attention networks Corbetta and Shulman 2002).

\footnotetext{
$\dagger$ ADHD-200 Sample; http://fcon_1000.projects.nitrc.org/indi/adhd200
} 


\section{MATERIAL AND METHODS}

\section{Dataset}

We selected 165 children out of the 255 children cohort (44 girls, 121 boys; 7-17 year old, $10.93 \pm 2.53$ years, FSIQ $>70$ ) with ADHD. Selection was based on the use of the same version of the Conner's Parent Rating Scale-Revised, Long version (CPRS-R). Consequently 90 children were rejected from participating in the study due to the absence of CPRS-R scores. These children were recruited from two centers: Kennedy Krieger Institute (KKI) or New York University (NYU). The children were diagnosed based on evaluations with the Diagnostic Interview for Children and Adolescents, Fourth Edition (DICA-IV Reich et al. 1997) or the Schedule of Affective Disorders and Schizophrenia for Children-Present and Lifetime Version (KSADS-PL); CPRS-R or ADHD Rating Scale-IV (DuPaul and Power 1998). They either had a T-score of 65 or greater on at least one ADHD related index of the CPRS-R, or met criteria on the ADHD Rating Scale-IV (six out of nine items scored 2 or 3 from Inattention items and/or six out of nine scored 2 or 3 from the Hyperactivity/Impulsivity items). Consistent with previous studies, children taking stimulant medication were instructed to refrain from taking these medications for at least 24 hours before scanning. Additionally we selected a control group of 170 children matched with our ADHD group (83 girls, 87 boys; 7-17 year old, $11.46 \pm 2.76$ years, FSIQ > 70). Details of the center distribution of the data included in the study are reported in Table 1. 


\section{Classification}

The CPRS-R is a validated and widely used parent questionnaire that assesses hyperactivity-impulsivity and inattention as well as a range of other problem behaviour in children and adolescents. We divided our population into three groups defined by the imbalance between their symptoms. We used K-means cluster analysis (Steinhaus 1957; Forgy 1965; MacQueen 1967; Hartigan and Wong 1979; Lloyd 1982) on the ratio between the hyperactivity-impulsivity and inattention CPRS-R scores to fractionate our sample into three subgroups: predominantly inattentive, predominantly hyperactive and combined. K-means clustering analysis is a commonly used approach to identify relatively homogeneous groups of cases or variables based on selected characteristics (Johansen-Berg et al. 2004; Anwander et al. 2007; Catani et al. 2007; Mars, Jbabdi, et al. 2011; Mars, Sallet, et al. 2011). This identified the following: 53 children with a predominantly inattentive CPRS score $(32 \%, 7-17$ year old, $11.28 \pm 2.75$ years, 34 males and 19 females); 44 children (27\%, 7-17 year old, $11.36 \pm 2.59$ years, 34 males and 10 females) with a predominantly hyperactive-impulsive CPRS score and 68 children (41\%, 7-16 year old, $10.39 \pm 2.24$ years, 53 males and 15 females) with a combined symptom profile. Demographical data are reported in Table 2.

\section{Magnetic resonance imaging data acquisition.}

During acquisition of the rs-fMRI, participants in both centers (i.e. KKI and NYU) were instructed to relax, think of nothing, and to stay awake. In KKI participants 
were asked to keep their eyes open, and fixate on a center cross, whereas in NYU participants were instructed to close their eyes. Functional images were obtained using T2-weighted echo-planar imaging (EPI) with blood oxygenation level-dependent (BOLD) contrast using SENSE imaging. In KKI, EPIs (TR/TE $=2500 / 30 \mathrm{msec})$ comprised 47 axial slices acquired continuously in ascending order covering the entire cerebrum $\left(\right.$ voxel size $\left.=2.67 \times 2.67 \times 3.00 \mathrm{~mm}^{3}\right)$. In NYU, EPIs $(T R / T E=2000 / 15 \mathrm{msec})$ comprised 33 axial slices acquired continuously in interleaved order covering the entire cerebrum $\left(\right.$ voxel size $\left.=3.0 \times 3.0 \times 4.0 \mathrm{~mm}^{3}\right)$.

An axial three-dimensional (3D) magnetization prepared rapid gradient echo (MPRAGE) dataset covering the whole head was also acquired for each participant (200 slices, voxel resolution $=1.00 \times 1.00 \times 1.00 \mathrm{~mm}, \mathrm{TE}=3.7 \mathrm{msec}, \mathrm{TR}=8.0 \mathrm{msec}$, flip angle $=8^{\circ}$ for KKI; 128 slices, voxel resolution $=1.3 \times 1.0 \times 1.3 \mathrm{~mm}, \mathrm{TE}=2530 \mathrm{msec}$, $\mathrm{TR}=3.25 \mathrm{msec}$, flip angle $=7^{\circ}$ for NYU).

rs- $f$ MRI independent component analysis Analysis of functional connectivity was carried out using Probabilistic Independent Component Analysis (PICA, Beckmann and Smith 2004; Beckmann 2012) as implemented in Multivariate Exploratory Linear Decomposition into Independent Components (MELODIC) version 3.13, part of FMRIB's Software Library (FSL, www.fmrib.ox.ac.uk/fsl). We chose PICA as it is a robust, operator independent approach(Beckmann and Smith 2004; Beckmann et al. 
2005; Beckmann et al. 2009), which provides a very close relationship between the anatomy of the resting networks identified and classical brain functional activations (Smith et al. 2009).

In order to obtain a steady-state signal, the five first volumes of each dataset were discarded from the analyses. Rs-fMRI datasets were corrected for head motion by rigid registration to the first volume (Jenkinson et al. 2002), capped with a high pass filter $(.01 \mathrm{~Hz}$, Gaussian-weighted least-squares straight line fitting, with sigma $=50.0 \mathrm{sec})$ and skull-stripped (Smith 2002). Each subject's fMRI data was registered to that subject's high-resolution structural image (Jenkinson et al.2002) and then registered again, this time, with the standard MNI152 template using affine (FLIRT) and non-linear registration (FNIRT). All resulting datasets were concatenated in the temporal dimension. This approach is advantageous, as it does not assume that the associated temporal response is consistent across subject but rather looks for common spatial patterns between subjects.

The following data pre-processing was applied to the input data: masking of non-brain voxels; voxel-wise de-meaning of the data; normalisation of the voxel-wise variance; pre-processed data were whitened and projected into a 23-dimensional subspace using probabilistic principal component analysis where the number of dimensions was estimated using the Laplace approximation to the Bayesian evidence of 
the model order (Minka 2000; Beckmann and Smith 2004).

We focused our analyses on three resting state networks of interest, the cortico-striatal network(Alexander et al. 1986; Nieuwenhuys et al. 2008), the dorsal and the ventral attention networks (i.e. DAN and VAN, Corbetta and Shulman 2002; Fox et al. 2006).

\section{rs- $f$ MRI Dual regressions}

In order to assess the presence of group differences in the spatial extent of the RSNs, it is necessary to generate subject-level maps of the components extracted by the group-level ICA. This is achieved in two steps: (1) first, the entire set of 23 group-level spatial components (Fig. 1) was regressed against each volume of the preprocessed rs- $f$ MRI data using multiple regression in the spatial domain; therefore, the $3 \mathrm{D}$ image associated with each time point in the rs-fMRI data was modeled as a linear combination of the group-level spatial components. This allowed for the estimation of a subject-specific time course for each group-level component. (2) Afterwards, the whole set of 23 component-specific time courses were used as predictors in a second multiple regression in the temporal domain, against the preprocessed rs-fMRI data of each subject. In this way we estimated the correlation of each brain voxel with the characteristic time course of each spatial component, and ultimately obtained maps of the spatial distribution of each subject-specific component. Since this procedure is based on two multiple 
regression steps, the first in the spatial domain, the second in the temporal domain, it has been denominated 'dual regression' (Filippini et al. 2009). A visual description of the steps of the dual regression can be found in (Beckmann et al. 2009). Importantly, since the full set of components extracted by ICA is used, the dual regression procedure accounts for the potential contamination of the rs- $f$ MRI signal by components reflecting structured noise such as motion artifacts and white matter signals. Therefore any variance shared between these components and the rs-fMRI networks of interest was regressed out during the estimation of the rs-fMRI networks summary time course for each subject. For instance, the white matter signal was modeled as the time course of the IC 8, and

subsequently, this component had been estimated in a subject-specific way - by means of the first stage of dual regression. This approach has several benefits with respect to using a standard mask of white matter. The white matter mask is directly estimated from the data: remarkably, this component is among the most reproducible found in different ICA-based resting state investigations (e.g. IC4 in (Biswal et al. 2010); BM20 in (Smith et al. 2009); IC31 in (Salimi-Khorshidi et al. 2014)). In addition, the dual regression procedure allows for an estimation of the subject-level component of the white matter component extracted in the group analysis.

We then tested for statistical differences between the inattentive group and the hyperactive group using FSL's randomise permutation-testing tool. Randomise calculates nonparametric inferences on neuroimaging data. For each voxel of the brain, randomise will test using a permuted general model (Winkler et al. 2014) whether the strength of the 
functional connectivity in the cortico-striatal, DAN and VAN networks (i.e. the

dependant variables) is different between the 'inattentive' and the 'hyperactive/impulsive'

groups (i.e. the independent variables). Results were corrected for multiple comparisons

using family-wise error (FWE) (Anderson and Robinson 2001; Nichols and Holmes

2002). 3D rendering of the brain was calculated using the T1 pipeline in Brain VISA

(http://brainvisa.info).

Note that recent work revealed that motion can have a substantial effect on the estimation of resting-state functional connectivity (Van Dijk et al. 2012). Removing time points associated with high motion ('scrubbing' Power et al. 2012) represents an effective procedure to reduce the contamination rs- $f$ MRI data by residual motion. However, performing 'scrubbing' before temporally-concatenated PICA is not technically feasible and, most importantly, not desirable, as it would lead to heteroschedasticity when performing group-level analysis (i.e., a different number of temporal degrees of freedom for each participant). In addition, a recent work (Jo et al. 2013) revealed that the largest contribution to minimizing head motion was yielded by regressing out from rs-fMRI data the mean signal in a white matter mask. 


\section{Statistical Analysis}

In our analysis, Gaussian distribution of the data for the three groups was confirmed using the Shapiro-Wilk test (Shapiro and Wilk 1965).

Statistical analysis was performed using SPSS 22 software (SPSS, Chicago, IL).

Analyses of the differences between the three groups were performed using repeated measure ANOVA for the clinical characteristics. Additionally, repeated measure ANOVA was employed to explore differences in the connectivity strength between the 4 groups in the regions reported as statistically different by the dual regression analysis. Gender, age, centre (KKI or NYU), verbal IQ, performance IQ, full IQ and movement during the rs-fMRI (absolute value) were considered as covariates. Note that there were no significant absolute movement differences between the 4 groups. Post-hoc independent sample t-tests were performed, when statistically appropriate, to compare groups individually. Differences significant at $\mathrm{P}<0.0042$ survived Bonferroni correction for multiple comparisons (12 post hoc comparisons for the clinical measures and the functional connectivity as reported in table 3 ).

\section{RESULTS}

The striatum represents an important relay station consisting of a group of parallel circuits connecting the cerebral cortex to the thalamus. Anatomically, it is possible to distinguish two main cortico-striatal loops (Alexander et al. 1986; Nieuwenhuys et al. 
2008). The direct loop includes, in sequence, excitatory corticostriatal, inhibitory striatopallidal (internal pallidum), inhibitory pallidothalamic and excitatory thalamo-cortical connections. The indirect loop sequentially includes the excitatory cortico-striatal, inhibitory striatopallidal (external palidum), inhibitory pallido-subthamalic, excitatory subthalamic-pallidal, inhibitory pallidothalamic and excitatory thalamocortical connections (Fig. 2). The overall function of these loops is to facilitate the initiation and execution of movement (Hauber 1998), the selection of purposeful patterns of movement in response to internal and environmental stimuli (Pessiglione et al. 2003), and reward and motivation (Pessiglione et al. 2006).

The cortico-striatal network we identified with rs-fMRI (component 5 in Fig. 1) mainly involved the frontal, parietal, posterior temporal and to some extent limbic cortices. Subcortically, it involved significantly the striatum, the internal and external pallidum, and the anterior portion of the thalamus. These results are comparable to those obtained in previously task related $f$ MRI (Jahanshahi et al. 2015) and rs-fMRI connectivity studies (Di Martino et al. 2008; Salomons et al. 2014)

The dorsal attentional network (i.e. DAN) increases its activation during the voluntary orienting of attention involving the frontal eye field, the intraparietal sulcus and superior parietal lobe. Alternatively, the ventral attentional network (i.e. VAN) acts as an alarm for the dorsal network, forcing the automatic reorientation of spatial attention when 
unexpected spatial events occur. The VAN classically involves the caudal portion of the inferior and middle frontal gyri and the supramarginal, angular and caudal portion of the superior temporal gyri (Corbetta and Shulman 2002; Shulman et al. 2010) (Fig. 3). The DAN we identified with rs-fMRI (component 9 in Fig. 1) involved mainly the frontal eye field, intraparietal sulcus and the superior parietal lobule. The VAN (component 11 in Fig. 1) involved the temporo-parietal junction (caudal superior temporal gyrus, supramarginal and angular gyri) and the posterior portion of the inferior frontal gyrus. These results are similar to those described as in previously task-related fMRI studies (Corbetta and Shulman 2002; Shulman et al. 2010) and rs-fMRI connectivity studies (Fox et al. 2006; Shulman et al. 2009; Hacker et al. 2013)

Repeated measures ANOVA revealed a significant interaction between the group and the CPRS scores $\left(\mathrm{F}_{(3,308)}=206.25 ; \mathrm{p}<0.001\right)$. Post-hoc independent-sample t-test are summarized in table 3 and revealed significant differences between the CPRS scores for the three groups (see Fig. 4).

Independent component analysis (ICA) identified the cortico-striatal (Fig. 5a,

Supplementary Material), dorsal and ventral attention resting state networks (Fig. 6a, Supplementary Material). The three networks showed a high inter-individual reproducibility reaching $100 \%$ for the core of each networks and each with a different power spectrum (Fig. 5b and 6b). Dual regression revealed that compared to the 
'inattentive' group, the 'hyperactive' group had stronger connectivity within the cortico-striatal network at the level of the right striatum (MNI coordinates 10,18,0;

volume $896 \mathrm{~mm}^{3}$; peak $\mathrm{p}=0.038$; situated in the head of the caudate nucleus as shown in Fig. 5c). This analysis also revealed that, compared to the 'hyperactive' group, the 'inattentive' group had stronger connectivity within the VAN in the core of its parietal (MNI coordinates 62,-30,40; volume $256 \mathrm{~mm}^{3}$; peak $\mathrm{p}=0.05$; Fig. 6c) and frontal components (MNI coordinates 58,14,8; volume $384 \mathrm{~mm}^{3}$; peak $\mathrm{p}=0.05$; Fig. 6c). The connectivity in the DAN, however, did not differ significantly between the 'inattentive' group, the 'hyperactive' group.

Repeated measures ANOVA revealed a significant interaction between the group membership and the strength of the connectivity in the areas reported by dual regression analysis as statistically different $\left(\mathrm{F}_{(3,308)}=14.059 ; \mathrm{p}<0.001\right)$. Post-hoc independent-sample t-test revealed significant differences between the strength of the connectivity for the three groups (see Fig. 5d, 6d and table 2). Additional analyses of the same regions mirrored in the left hemisphere were not significant $\left(\mathrm{F}_{(3,308)}=14.059 ; \mathrm{p}<\right.$ $0.001)$.

\section{DISCUSSION}

Our rs-fMRI study revealed, for the first time, a double dissociation between functional brain networks modulating hyperactivity/impulsivity and inattention in 
children with ADHD. In children with a predominantly hyperactive-impulsive subtype, we report increased connectivity in the right cortico-striatal network; whereas in those with a predominantly inattentive subtype, we found increased connectivity in the right ventral attention network. Additional analyses did not reveal significant differences in the same regions mirrored in the left hemisphere, further suggesting a right lateralised disturbance of these networks. These findings are consistent with our current understanding of the specific role of these networks and lateralization of specific cognitive function.

Previous neuropsychological, task-fMRI and anatomical studies have, for example, reported that attention is dominant in the right hemisphere (Sperry 1974; Mesulam 1999; Shulman et al. 2010; Thiebaut de Schotten et al. 2011). Also, the right hemispheric hypoarousal theory of ADHD has long suggested that inattention and impulsivity associated with $\mathrm{ADHD}$ is due to a lateralised disturbance in frontal lobe network function, mediated by the dysfunction of predominantly right hemispheric frontostriatal (Sheppard et al. 1999) and frontoparietal tracts (Carter et al. 1995). However, most prior studies lacked the statistical power to fractionate the ADHD phenotype further, and analyse the relationship between core symptoms of ADHD and these specific brain networks.

The specificity of our findings is consistent with earlier studies, which have reported that the corticostriatal system (predominantly modulated by dopamine) is central to 
hyperactivity and impulse control. For example, in animal studies, mice with neonatal dopamine-depleting lesions demonstrate hyperactivity that is reduced by psychostimulants (Avale et al. 2004) and infusions of a D1 antagonist into the prefrontal cortex of monkeys increase impulsivity (Ma et al. 2003; Ma et al. 2005). In children, psychostimulants have been reported to be associated with reduced inferior frontal lobe activation during inhibition related tasks (Pauls et al. 2012). Further, in children with ADHD, increased impulsivity has been reported to be associated with atypical fronto-striatal function (Durston et al. 2003), task related reduced activations (Cubillo et al. 2010), decreased entropy (Sokunbi et al. 2013), and increased rs-fMRI connectivity (Costa Dias et al. 2013). Therefore the increased connectivity reported in our study may contribute to the overall lack of response control (i.e. hyperactivity and impulsivity) found in ADHD patients. In contrast with our results, fronto-striatal functional connectivity has been reported to be reduced in ADHD during task-related fMRI but is 'normalized' with the use of stimulant (Rubia et al. 2009). Methodological differences between the current approach and previous studies may explain this discrepancy; alternatively aberrant connectivity may behave differently during rest or task-related $f$ MRI.

Conversely the VAN, predominantly modulated by noradrenaline, has been more closely linked with attention and the control of switching attention from one source to another (Aston-Jones et al. 1984; Corbetta and Shulman 2002; Bouret and Sara 2005). Studies in 
monkeys, for example, have reported noradrenergic innervation of the temporo-parietal junction and the frontal lobe by the locus coeruleus/noradrenergic system (Morrison and Foote 1986; Foote and Morrison 1987). Functionally, this serves to reorient an individual to salient or behaviourally relevant visual, auditory or tactile stimuli (Downar et al. 2000). Also, the modulation of inferior frontal gyrus activation with stimulant during presentation of irrelevant distractors covaries with activation within the ventral fronto-parietal network (Pauls et al. 2012). Therefore the increased connectivity reported in our study may contribute to the excessive reorientation to irrelevant distracters (i.e. distractibility or inattention) found in $\mathrm{ADHD}$ patients(for a review on the noradrenergic system and the ventral attention system see Corbetta et al. 2008). Further, during spatial tasks fronto-parietal functional connectivity has been reported to be reduced in subjects with ADHD (Vloet et al. 2010) again suggesting that aberrant functional connectivity may be different at rest and during a task.

Increased aberrant connectivity within the cortico-striatal and VAN might be related to a delayed synaptic pruning that occurs during brain maturation (Low and Cheng 2006). Preliminary reports show that ADHD children are on a different trajectory of brain maturation (Shaw et al. 2012) that may also have impacted the functional connectivity within the cortico-striatal and ventral fronto-parietal networks. Alternatively, increased functional connectivity may also be related to compensatory mechanisms (for a similar interpretation in posterior cerebral atrophy see Migliaccio et al. 2016). 
Although the current study has a number of strengths it also had some limitations. First, in order to increase statistical power, we combined datasets from two different institutes. This approach produced some inhomogeneity in the dataset (e.g., spatial and temporal resolution of rs-fMRI and structural MRI, eyes opened/closed during resting state, etc.). However, it is unlikely that this has had a significant effect on our results as the networks identified by rs-fMRI are extraordinarily robust across distinct populations and differences in scanner field strength, scanning parameters (Biswal et al.2010), or condition of rest (eyes opened or closed Patriat et al. 2013) and are stable in test-retest designs (Shehzad et al. 2009; Van Dijk et al. 2010). Further the children in the two centres were matched for age, sex and clinical characteristics. A second limitation was the absence of information regarding co-morbid diagnoses (e.g., conduct disorders) and medication status (e.g., medication naïve/not naïve) for many subjects. This effect has been minimized as stimulant drugs were withdrawn at least 24 hours before scanning. However, these factors may still have confounded our findings if they were not randomly distributed between the two groups (Shafritz et al. 2004; An, Cao, Cao, et al. 2013; Zhu et al. 2013). Future studies would benefit from clearer measures of these factors. A third limitation is the hypothetically driven aspect of our study, which purposely focused on the cortico-striatal and attentional networks in order to reduce the number of comparisons. Other studies report strong functional connectivity differences, between ADHD and controls, in the default network, particularly in the anterior cingulate cortex (Tian et al. 
2006; Castellanos et al. 2008; Wolf et al. 2009; Fair et al. 2010) and cortico-cerebellar network (Cao et al. 2006; Tian et al. 2006; Zang et al. 2007; Rubia et al. 2009; Wolf et al. 2009). Future research may need to explore further these networks with probabilistic independent component analysis or other approaches such as fractal analysis, entropy and complexity measurements and frequency analysis techniques, which recently provided interesting brain behavior correlations in ADHD (Zang et al. 2007; An, Cao, Sui, et al. 2013; Sokunbi et al. 2013). Finally, it is important to note that our group division suggests that a continuum exists between the different symptoms dimension in ADHD. It is important to note that we use a statistical clustering (k-mean clustering) based on CPRS-R scores rather than the original subtypes classified in the ADHD-200 sample in order to reduce variability in the subtype diagnosis. Our purpose was not to provide a new classification of ADHD but rather to identify the biological mechanisms that lead to profiles that are more hyperactive than inattentive or more inattentive than hyperactive.

In summary our study demonstrated for the first time a right lateralized, double dissociation between specific networks associated with hyperactivity-impulsivity and inattentiveness in children with ADHD. The measure of increased functional connectivity in the cortico-striatal or ventral fronto-parietal networks may assist further studies to fractionate the ADHD phenotype into more homogenous biological subtypes. 


\section{ACKDOWLEDGEMENTS}

We would like to thank the NATBRAINLAB (http://www.natbrainlab.com) and

Huai-Hsuan Tseng for helpful discussion. This work was supported by The Japan

Foundation for Pediatric Research, Shire (project IST-ALB-000217), and the Agence

Nationale de la Recherche (project PHENOTYPES, no. ANR-13-JSV4-0001-01).

\section{REFERENCES}

Alexander GE, DeLong MR, Strick PL. 1986. Parallel organization of functionally segregated circuits linking basal ganglia and cortex. Annu Rev Neurosci 9:357-381. American Psychiatric Association. 1994. Diagnostic and Statistical Manual of Mental Disorders. Washington, DC: American Psychiatric Association.

American Psychiatric Association. 2013. Diagnostic and statistical manual of mental disorders. Washington, DC.

An L, Cao QJ, Sui MQ, Sun L, Zou QH, Zang YF, Wang YF. 2013. Local synchronization and amplitude of the fluctuation of spontaneous brain activity in attention-deficit/hyperactivity disorder: a resting-state fMRI study. Neuroscience bulletin 29:603-613.

An L, Cao XH, Cao QJ, Sun L, Yang L, Zou QH, Katya R, Zang YF, Wang YF. 2013. Methylphenidate normalizes resting-state brain dysfunction in boys with attention deficit hyperactivity disorder. Neuropsychopharmacology 38:1287-1295.

Anderson M, Robinson J. 2001. Permutation test for linear models Aust NZ J Stat 43:75-88.

Anwander A, Tittgemeyer M, von Cramon DY, Friederici AD, Knösche TR. 2007. Connectivity-Based Parcellation of Broca's Area. Cereb Cortex 17:816-825.

Aston-Jones G, Foote SL, Bloom FE. 1984. Frontiers of Clinical Neuroscience.

Baltimore, Maryland: Williams \& Wilkins.

Avale ME, Falzone TL, Gelman DM, Low MJ, Grandy DK, Rubinstein M. 2004. The dopamine D4 receptor is essential for hyperactivity and impaired behavioral inhibition in a mouse model of attention deficit/hyperactivity disorder. Mol Psychiatry 9:718-726.

Barkley R, Fischer M, Smallish L, Fletcher K. 2002. The persistence of attentiondeficit/hyperactivity disorder into young adulthood as a function of reporting source and definition of disorder. Journal of Abnormal Psychology 111:279-289.

Beckmann CF. 2012. Modelling with independent components. Neuroimage 62:891-901.

Beckmann CF, DeLuca M, Devlin JT, Smith SM. 2005. Investigations into resting-state connectivity using independent component analysis. Philosophical transactions of the 
Royal Society of London Series B, Biological sciences 360:1001-1013.

Beckmann CF, Mackay CE, Filippini N, Smith SM. 2009. Group comparison of resting-state FMRI data using multi-subject ICA and dual regression. OHBM.

Beckmann CF, Smith SM. 2004. Probabilistic independent component analysis for functional magnetic resonance imaging. IEEE transactions on medical imaging 23:137-152.

Biederman J, Mick E, Surman C, Doyle R, Hammerness P, Harpold T, Dunkel S, Dougherty M, Aleardi M, Spencer T. 2006. A randomized, placebo-controlled trial of OROS methylphenidate in adults with attention-deficit/hyperactivity disorder. Biol Psychiatry 59:829-835.

Biswal BB, Mennes M, Zuo XN, Gohel S, Kelly C, Smith SM, Beckmann CF, Adelstein JS, Buckner RL, Colcombe S, Dogonowski AM, Ernst M, Fair D, Hampson M, Hoptman MJ, Hyde JS, Kiviniemi VJ, Kotter R, Li SJ, Lin CP, Lowe MJ, Mackay C, Madden DJ, Madsen KH, Margulies DS, Mayberg HS, McMahon K, Monk CS, Mostofsky SH, Nagel BJ, Pekar JJ, Peltier SJ, Petersen SE, Riedl V, Rombouts SA, Rypma B, Schlaggar BL, Schmidt S, Seidler RD, Siegle GJ, Sorg C, Teng GJ, Veijola J, Villringer A, Walter M, Wang L, Weng XC, Whitfield-Gabrieli S, Williamson P, Windischberger C, Zang YF, Zhang HY, Castellanos FX, Milham MP. 2010. Toward discovery science of human brain function. Proc Natl Acad Sci U S A 107:4734-4739.

Bloom B, Cohen RA, Freeman G. 2011. Summary health statistics for U.S. children: National Health Interview Survey, 2010. Vital and health statistics Series 10, Data from the National Health Survey:1-80.

Bouret S, Sara SJ. 2005. Network reset: a simplified overarching theory of locus coeruleus noradrenaline function. Trends Neurosci 28:574-582.

Buckholtz JW, Treadway MT, Cowan RL, Woodward ND, Li R, Ansari MS, Baldwin RM, Schwartzman AN, Shelby ES, Smith CE, Kessler RM, Zald DH. 2010.

Dopaminergic network differences in human impulsivity. Science 329:532.

Bush G. 2011. Cingulate, frontal, and parietal cortical dysfunction in attention-deficit/hyperactivity disorder. Biol Psychiatry 69:1160-1167.

Cao Q, Zang Y, Sun L, Sui M, Long X, Zou Q, Wang Y. 2006. Abnormal neural activity in children with attention deficit hyperactivity disorder: a resting-state functional magnetic resonance imaging study. Neuroreport 17:1033-1036.

Carter CS, Krener P, Chaderjian M, Northcutt C, Wolfe V. 1995. Asymmetrical visual-spatial attentional performance in ADHD: evidence for a right hemispheric deficit. Biol Psychiatry 37:789-797.

Castellanos FX, Margulies DS, Kelly C, Uddin LQ, Ghaffari M, Kirsch A, Shaw D, Shehzad Z, Di Martino A, Biswal B, Sonuga-Barke EJ, Rotrosen J, Adler LA, Milham MP. 2008. Cingulate-precuneus interactions: a new locus of dysfunction in adult attention-deficit/hyperactivity disorder. Biol Psychiatry 63:332-337.

Catani M, Allin MP, Husain M, Pugliese L, Mesulam MM, Murray RM, Jones DK. 2007. Symmetries in human brain language pathways correlate with verbal recall. Proc Natl Acad Sci U S A 104:17163-17168. 
Catani M, Thiebaut de Schotten M. 2012. Atlas of Human Brain Connections. Oxford: Oxford University Press.

Corbetta M, Patel G, Shulman GL. 2008. The reorienting system of the human brain: from environment to theory of mind. Neuron 58:306-324.

Corbetta M, Shulman GL. 2002. Control of goal-directed and stimulus-driven attention in the brain. Nature Reviews Neuroscience 3:201-215.

Cortese S, Kelly C, Chabernaud C, Proal E, Di Martino A, Milham MP, Castellanos FX. 2012. Toward systems neuroscience of ADHD: a meta-analysis of $55 \mathrm{fMRI}$ studies. Am J Psychiatry 169:1038-1055.

Costa Dias TG, Wilson VB, Bathula DR, Iyer SP, Mills KL, Thurlow BL, Stevens CA, Musser ED, Carpenter SD, Grayson DS, Mitchell SH, Nigg JT, Fair DA. 2013. Reward circuit connectivity relates to delay discounting in children with attention-deficit/hyperactivity disorder. European neuropsychopharmacology : the journal of the European College of Neuropsychopharmacology 23:33-45.

Crichton A. 1798. An inquiry into the nature and origin of mental derangement: comprehending a concise system of the physiology and pathology of the human mind and a history of the passions and their effects. Cadell T Jr, Davies W, London.

Crichton A. 2008. An inquiry into the nature and origin of mental derangement. Journal of attention disorders 12:200-204.

Cubillo A, Halari R, Ecker C, Giampietro V, Taylor E, Rubia K. 2010. Reduced activation and inter-regional functional connectivity of fronto-striatal networks in adults with childhood Attention-Deficit Hyperactivity Disorder (ADHD) and persisting symptoms during tasks of motor inhibition and cognitive switching. Journal of psychiatric research 44:629-639.

Cubillo A, Halari R, Smith A, Taylor E, Rubia K. 2012. A review of fronto-striatal and fronto-cortical brain abnormalities in children and adults with Attention Deficit Hyperactivity Disorder (ADHD) and new evidence for dysfunction in adults with ADHD during motivation and attention. Cortex 48:194-215.

Di Martino A, Scheres A, Margulies DS, Kelly AM, Uddin LQ, Shehzad Z, Biswal B, Walters JR, Castellanos FX, Milham MP. 2008. Functional connectivity of human striatum: a resting state FMRI study. Cereb Cortex 18:2735-2747.

Dickstein SG, Bannon K, Castellanos FX, Milham MP. 2006. The neural correlates of attention deficit hyperactivity disorder: an ALE meta-analysis. Journal of child psychology and psychiatry, and allied disciplines 47:1051-1062.

Downar J, Crawley AP, Mikulis DJ, Davis KD. 2000. A multimodal cortical network for the detection of changes in the sensory environment. Nat Neurosci 3:277-283.

DuPaul GJ, Power TJ. 1998. ADHD Rating Scale IV: checklist, norms and clinical interpretation. New York: Guilford Press.

Durston S, Tottenham NT, Thomas KM, Davidson MC, Eigsti IM, Yang Y, Ulug AM, Casey BJ. 2003. Differential patterns of striatal activation in young children with and without ADHD. Biol Psychiatry 53:871-878.

Fair DA, Nigg JT, Iyer S, Bathula D, Mills KL, Dosenbach NU, Schlaggar BL, Mennes 
M, Gutman D, Bangaru S, Buitelaar JK, Dickstein DP, Di Martino A, Kennedy DN, Kelly C, Luna B, Schweitzer JB, Velanova K, Wang YF, Mostofsky S, Castellanos FX, Milham MP. 2012. Distinct neural signatures detected for ADHD subtypes after controlling for micro-movements in resting state functional connectivity MRI data. Frontiers in systems neuroscience 6:80.

Fair DA, Posner J, Nagel BJ, Bathula D, Dias TG, Mills KL, Blythe MS, Giwa A, Schmitt CF, Nigg JT. 2010. Atypical default network connectivity in youth with attention-deficit/hyperactivity disorder. Biol Psychiatry 68:1084-1091.

Filippini N, MacIntosh BJ, Hough MG, Goodwin GM, Frisoni GB, Smith SM, Matthews PM, Beckmann CF, Mackay CE. 2009. Distinct patterns of brain activity in young carriers of the APOE-epsilon4 allele. Proc Natl Acad Sci U S A 106:7209-7214.

Foote SL, Morrison JH. 1987. Extrathalamic modulation of cortical function. Annu Rev Neurosci 10:67-95.

Forgy EW. 1965. Cluster analysis of multivariate data: efficiency versus interpretability of classifications. Biometrics 21:768-769.

Fox MD, Corbetta M, Snyder AZ, Vincent JL, Raichle ME. 2006. Spontaneous neuronal activity distinguishes human dorsal and ventral attention systems. P Natl Acad Sci USA 103:10046-10051.

Fox MD, Raichle ME. 2007. Spontaneous fluctuations in brain activity observed with functional magnetic resonance imaging. Nat Rev Neurosci 8:700-711.

Hacker CD, Laumann TO, Szrama NP, Baldassarre A, Snyder AZ, Leuthardt EC, Corbetta M. 2013. Resting state network estimation in individual subjects. Neuroimage 82:616-633.

Hamilton LS, Levitt JG, O'Neill J, Alger JR, Luders E, Phillips OR, Caplan R, Toga AW, McCracken J, Narr KL. 2008. Reduced white matter integrity in attention-deficit hyperactivity disorder. Neuroreport 19:1705-1708.

Hartigan JA, Wong MA. 1979. Algorithm AS 136: A K-Means Clustering Algorithm. Journal of the Royal Statistical Society, Series C 28:100-108.

Hauber W. 1998. Involvement of basal ganglia transmitter systems in movement initiation. Prog Neurobiol 56:507-540.

Hazell PL, Kohn MR, Dickson R, Walton RJ, Granger RE, Wyk GW. 2011. Core ADHD symptom improvement with atomoxetine versus methylphenidate: a direct comparison meta-analysis. Journal of attention disorders 15:674-683.

Jahanshahi M, Obeso I, Rothwell JC, Obeso JA. 2015. A

fronto-striato-subthalamic-pallidal network for goal-directed and habitual inhibition. Nat Rev Neurosci 16:719-732.

Jenkinson M, Bannister P, Brady M, Smith S. 2002. Improved optimization for the robust and accurate linear registration and motion correction of brain images. Neuroimage 17:825-841.

Jo HJ, Gotts SJ, Reynolds RC, Bandettini PA, Martin A, Cox RW, Saad ZS. 2013. Effective Preprocessing Procedures Virtually Eliminate Distance-Dependent Motion Artifacts in Resting State FMRI. Journal of applied mathematics 2013. 
Johansen-Berg H, Behrens TEJ, Robson MD, Drobnjak I, Rushworth MFS, Brady JM, Smith SM, Higham DJ, Matthews PM. 2004. Changes in connectivity profiles define functionally distinct regions in human medial frontal cortex. Proc Natl Acad Sci USA 101:13335-13340.

Kessler RC, Adler L, Barkley R, Biederman J, Conners CK, Demler O, Faraone SV, Greenhill LL, Howes MJ, Secnik K, Spencer T, Ustun TB, Walters EE, Zaslavsky AM. 2006. The prevalence and correlates of adult ADHD in the United States: results from the National Comorbidity Survey Replication. Am J Psychiatry 163:716-723.

Konrad A, Dielentheis TF, El Masri D, Bayerl M, Fehr C, Gesierich T, Vucurevic G, Stoeter P, Winterer G. 2010. Disturbed structural connectivity is related to inattention and impulsivity in adult attention deficit hyperactivity disorder. Eur J Neurosci 31:912-919.

Lange KW, Reichl S, Lange KM, Tucha L, Tucha O. 2010. The history of attention deficit hyperactivity disorder. Atten Defic Hyperact Disord 2:241-255.

Lloyd SP. 1982. Least squares quantization in PCM. IEEE Transactions on Information Theory 28:129-137.

Low LK, Cheng HJ. 2006. Axon pruning: an essential step underlying the developmental plasticity of neuronal connections. Philosophical transactions of the Royal Society of London Series B, Biological sciences 361:1531-1544.

Luders E, Narr KL, Hamilton LS, Phillips OR, Thompson PM, Valle JS, Del'Homme M, Strickland T, McCracken JT, Toga AW, Levitt JG. 2009. Decreased callosal thickness in attention-deficit/hyperactivity disorder. Biol Psychiatry 65:84-88.

Ma CL, Arnsten AF, Li BM. 2005. Locomotor hyperactivity induced by blockade of prefrontal cortical alpha2-adrenoceptors in monkeys. Biol Psychiatry 57:192-195.

Ma CL, Qi XL, Peng JY, Li BM. 2003. Selective deficit in no-go performance induced by blockade of prefrontal cortical alpha 2-adrenoceptors in monkeys. Neuroreport 14:1013-1016.

MacQueen JB. 1967. Some Methods for classification and Analysis of Multivariate Observations. In. Proceedings of 5-th Berkeley Symposium on Mathematical Statistics and Probability Berkeley: University of California Press p 281-297.

Makris N, Buka SL, Biederman J, Papadimitriou GM, Hodge SM, Valera EM, Brown AB, Bush G, Monuteaux MC, Caviness VS, Kennedy DN, Seidman LJ. 2008. Attention and executive systems abnormalities in adults with childhood ADHD: A DT-MRI study of connections. Cereb Cortex 18:1210-1220.

Mars RB, Jbabdi S, Sallet J, O'Reilly JX, Croxson PL, Olivier E, Noonan MP, Bergmann C, Mitchell AS, Baxter MG, Behrens TE, Johansen-Berg H, Tomassini V, Miller KL, Rushworth MF. 2011. Diffusion-weighted imaging tractography-based parcellation of the human parietal cortex and comparison with human and macaque resting-state functional connectivity. J Neurosci 31:4087-4100.

Mars RB, Sallet J, Schuffelgen U, Jbabdi S, Toni I, Rushworth MF. 2011. Connectivity-Based Subdivisions of the Human Right "Temporoparietal Junction Area": Evidence for Different Areas Participating in Different Cortical Networks. Cereb 
Cortex.

Mesulam MM. 1999. Spatial attention and neglect: parietal, frontal and cingulate contributions to the mental representation and attentional targeting of salient extrapersonal events. Philos Trans R Soc Lond, B, Biol Sci 354:1325-1346.

Migliaccio R, Gallea C, Kas A, Perlbarg V, Samri D, Trotta L, Michon A, Lacomblez L, Dubois B, Lehericy S, Bartolomeo P. 2016. Functional Connectivity of Ventral and Dorsal Visual Streams in Posterior Cortical Atrophy. J Alzheimers Dis.

Minka T. 2000. Automatic choice of dimensionality for PCA. Technical Report 514, MIT Media Lab Vision and Modeling Group.

Morrison JH, Foote SL. 1986. Noradrenergic and serotoninergic innervation of cortical, thalamic, and tectal visual structures in Old and New World monkeys. J Comp Neurol 243:117-138.

Nichols TE, Holmes AP. 2002. Nonparametric permutation tests for functional neuroimaging: a primer with examples. Hum Brain Mapp 15:1-25.

Nieuwenhuys R, Voogd J, van Huijzen C. 2008. The human central nervous system. Berlin ; New York: Springer.

Patriat R, Molloy EK, Meier TB, Kirk GR, Nair VA, Meyerand ME, Prabhakaran V, Birn RM. 2013. The effect of resting condition on resting-state fMRI reliability and consistency: a comparison between resting with eyes open, closed, and fixated. Neuroimage 78:463-473.

Pauls AM, O'Daly OG, Rubia K, Riedel WJ, Williams SC, Mehta MA. 2012. Methylphenidate effects on prefrontal functioning during attentional-capture and response inhibition. Biol Psychiatry 72:142-149.

Pessiglione M, Guehl D, Agid Y, Hirsch EC, Feger J, Tremblay L. 2003. Impairment of context-adapted movement selection in a primate model of presymptomatic Parkinson's disease. Brain 126:1392-1408.

Pessiglione M, Seymour B, Flandin G, Dolan RJ, Frith CD. 2006. Dopamine-dependent prediction errors underpin reward-seeking behaviour in humans. Nature 442:1042-1045.

Power JD, Barnes KA, Snyder AZ, Schlaggar BL, Petersen SE. 2012. Spurious but systematic correlations in functional connectivity MRI networks arise from subject motion. Neuroimage 59:2142-2154.

Reich W, Leacock N, Shanfeld K. 1997. DICA-IV Diagnostic Interview for Children and Adolescents-IV. Tronto, Ontario: Multi-Health Systems, Inc.

Rubia K. 2011. "Cool" inferior frontostriatal dysfunction in attention-deficit/hyperactivity disorder versus "hot" ventromedial orbitofrontal-limbic dysfunction in conduct disorder: a review. Biol Psychiatry 69:e69-87.

Rubia K, Halari R, Cubillo A, Mohammad AM, Brammer M, Taylor E. 2009.

Methylphenidate normalises activation and functional connectivity deficits in attention and motivation networks in medication-naive children with ADHD during a rewarded continuous performance task. Neuropharmacology 57:640-652.

Salimi-Khorshidi G, Douaud G, Beckmann CF, Glasser MF, Griffanti L, Smith SM. 2014. 
Automatic denoising of functional MRI data: combining independent component analysis and hierarchical fusion of classifiers. Neuroimage 90:449-468.

Salomons TV, Dunlop K, Kennedy SH, Flint A, Geraci J, Giacobbe P, Downar J. 2014. Resting-state cortico-thalamic-striatal connectivity predicts response to dorsomedial prefrontal rTMS in major depressive disorder. Neuropsychopharmacology 39:488-498.

Shafritz KM, Marchione KE, Gore JC, Shaywitz SE, Shaywitz BA. 2004. The effects of methylphenidate on neural systems of attention in attention deficit hyperactivity disorder. Am J Psychiatry 161:1990-1997.

Shapiro S, Wilk M. 1965. An Analysis of Variance Test for Normality (Complete Samples). Biometrika 52:591-611.

Shaw P, Malek M, Watson B, Sharp W, Evans A, Greenstein D. 2012. Development of cortical surface area and gyrification in attention-deficit/hyperactivity disorder. Biol Psychiatry 72:191-197.

Shehzad Z, Kelly AM, Reiss PT, Gee DG, Gotimer K, Uddin LQ, Lee SH, Margulies DS, Roy AK, Biswal BB, Petkova E, Castellanos FX, Milham MP. 2009. The resting brain: unconstrained yet reliable. Cereb Cortex 19:2209-2229.

Sheppard DM, Bradshaw JL, Mattingley JB, Lee P. 1999. Effects of stimulant medication on the lateralisation of line bisection judgements of children with attention deficit hyperactivity disorder. J Neurol Neurosurg Psychiatry 66:57-63.

Shulman GL, Astafiev SV, Franke D, Pope DL, Snyder A, McAvoy MP, Corbetta M. 2009. Interaction of stimulus-driven reorienting and expectation in ventral and dorsal frontoparietal and Basal Ganglia-cortical networks. Journal of Neuroscience 29:4392-4407.

Shulman GL, Pope DL, Astafiev SV, McAvoy MP, Snyder AZ, Corbetta M. 2010. Right hemisphere dominance during spatial selective attention and target detection occurs outside the dorsal frontoparietal network. Journal of Neuroscience 30:3640-3651.

Smith SM. 2002. Fast robust automated brain extraction. Hum Brain Mapp 17:143-155. Smith SM, Fox PT, Miller KL, Glahn DC, Fox PM, Mackay CE, Filippini N, Watkins KE, Toro R, Laird AR, Beckmann CF. 2009. Correspondence of the brain's functional architecture during activation and rest. Proc Natl Acad Sci U S A 106:13040-13045.

Sokunbi MO, Fung W, Sawlani V, Choppin S, Linden DE, Thome J. 2013. Resting state fMRI entropy probes complexity of brain activity in adults with ADHD. Psychiatry Res 214:341-348.

Spencer T, Wilens T, Biederman J, Faraone SV, Ablon JS, Lapey K. 1995. A double-blind, crossover comparison of methylphenidate and placebo in adults with childhood-onset attention-deficit hyperactivity disorder. Arch Gen Psychiatry 52:434-443.

Sperry RW. 1974. Lateral Specialization in the Surgically Separated Hemispheres. New York: Rockefeller University Press.

Steinhaus H. 1957. Sur la division des corps matériels en parties. Bull Acad Polon Sci 4:801-804.

Thiebaut de Schotten M, Dell'Acqua F, Forkel SJ, Simmons A, Vergani F, Murphy DG, Catani M. 2011. A lateralized brain network for visuospatial attention. Nat Neurosci 
$14: 1245-1246$.

Tian L, Jiang T, Wang Y, Zang Y, He Y, Liang M, Sui M, Cao Q, Hu S, Peng M, Zhuo Y. 2006. Altered resting-state functional connectivity patterns of anterior cingulate cortex in adolescents with attention deficit hyperactivity disorder. Neuroscience letters 400:39-43.

Uddin LQ, Kelly AM, Biswal BB, Margulies DS, Shehzad Z, Shaw D, Ghaffari M, Rotrosen J, Adler LA, Castellanos FX, Milham MP. 2008. Network homogeneity reveals decreased integrity of default-mode network in ADHD. J Neurosci Methods 169:249-254.

Van Dijk KR, Hedden T, Venkataraman A, Evans KC, Lazar SW, Buckner RL. 2010. Intrinsic functional connectivity as a tool for human connectomics: theory, properties, and optimization. J Neurophysiol 103:297-321.

Van Dijk KR, Sabuncu MR, Buckner RL. 2012. The influence of head motion on intrinsic functional connectivity MRI. Neuroimage 59:431-438.

Vloet TD, Gilsbach S, Neufang S, Fink GR, Herpertz-Dahlmann B, Konrad K. 2010. Neural mechanisms of interference control and time discrimination in attention-deficit/hyperactivity disorder. J Am Acad Child Adolesc Psychiatry 49:356-367.

Weiss M, Tannock R, Kratochvil C, Dunn D, Velez-Borras J, Thomason C, Tamura R, Kelsey D, Stevens L, Allen AJ. 2005. A randomized, placebo-controlled study of once-daily atomoxetine in the school setting in children with ADHD. Journal of the American Academy of Child and Adolescent Psychiatry 44:647-655.

Winkler AM, Ridgway GR, Webster MA, Smith SM, Nichols TE. 2014. Permutation inference for the general linear model. Neuroimage 92:381-397.

Wolf RC, Plichta MM, Sambataro F, Fallgatter AJ, Jacob C, Lesch KP, Herrmann MJ, Schonfeldt-Lecuona C, Connemann BJ, Gron G, Vasic N. 2009. Regional brain activation changes and abnormal functional connectivity of the ventrolateral prefrontal cortex during working memory processing in adults with attention-deficit/hyperactivity disorder. Hum Brain Mapp 30:2252-2266.

Zang YF, He Y, Zhu CZ, Cao QJ, Sui MQ, Liang M, Tian LX, Jiang TZ, Wang YF. 2007. Altered baseline brain activity in children with ADHD revealed by resting-state functional MRI. Brain Dev 29:83-91.

Zhu Y, Gao B, Hua J, Liu W, Deng Y, Zhang L, Jiang B, Zang Y. 2013. Effects of methylphenidate on resting-state brain activity in normal adults: an fMRI study. Neuroscience bulletin 29:16-27.

\section{FIGURE LEGENDS}

Fig. 1: 23 rs-fMRI networks extracted by the independent component analysis. Results 
are displayed in radiological convention (left = right).

Fig. 2: Diagram of the direct (cortico-triatal-pallido-thalamo-cortical) and indirect (cortico-striatal-pallido-subthalamic-pallido-thalamo-cortical) loops connecting the cerebral cortex to the basal ganglia and thalamus (Catani and Thiebaut de Schotten 2012).

Fig. 3: The dorsal (in blue) and ventral (in orange) fronto-parietal networks for visuospatial attention as identified by functional neuroimaging (Corbetta and Shulman 2002).

Fig. 4 K-mean clustering of ADHD patients based on inattentiveness and hyperactivity-impulsivity scores in Conner's Parent Rating Scale-Revised, Long version (CPRS-R). Error bars indicate $95 \%$ confidence intervals. $\quad * \mathrm{p}<0.0042$

Fig. 5 Cortico-striatal network. a) group effect of the cortico-striatal network as defined by ICA. b) Power spectrum of the cortico-striatal network according to time frequencies.

c) The right striatum shows an increased functional connectivity in the group 'hyperactive/impulsive' when compared to the group 'inattentive' for the cortico-striatal network. Note that coronal sections are displayed in radiological convention (left $=$ right).

d) Average functional connectivity in the cluster reported as significant in the striatum. 
Error bars indicate $95 \%$ confidence intervals. $* \mathrm{p}<0.0042$; SN, substantia nigra; Str, striatum; D1, receptor $\mathrm{D}_{1}$; D2, receptor $\mathrm{D}_{2}$; $\mathrm{EP}$, external pallidum; IP, internal pallidum; STN, subthalamic nucleus.

Fig. 6 Dorsal (DAN) and ventral (VAN) attention networks a) group effect of the DAN (blue to light blue) and VAN networks (red to yellow) as defined by ICA. b) Power spectrum of the DAN (blue) and the VAN (orange) according to time frequencies. c) The VAN shows an increased functional connectivity in the group 'inattentive' when compared to the group 'hyperactive/impulsive'. d) Average functional connectivity in the clusters reported as significant in the VAN. Error bars indicate $95 \%$ confidence intervals. $* \mathrm{p}<0.0042$. IPs: intraparietal sulcus; SPL: superior parietal lobule, FEF: frontal eye field, TPJ: temporo-parietal junction, IPL: inferior parietal lobule, STg: superior temporal gyrus, VFC: ventral frontal cortex, IFg: inferior frontal gyrus, MFg: middle frontal gyrus. 
Table 1: Centers demographics

\begin{tabular}{|c|c|c|c|c|c|c|c|c|c|}
\hline & $\mathrm{N}$ & $\sigma^{\lambda}$ & q & Age (y) & VIQ & PIQ & FSIQ & $>$ Inatt & $>$ Hyp/imp \\
\hline Total & 165 & 121 & 44 & $11.2 \pm 2.8$ & $107.2 \pm 14.5$ & $103.8 \pm 14.7$ & $105.7 \pm 14.3$ & 53 & 44 \\
\hline KKI (patients) & 22 & 12 & 10 & $10.2 \pm 1.5$ & $109.3 \pm 17.7$ & $109.4 \pm 13.8$ & $106.0 \pm 14.8$ & 4 & 7 \\
\hline KKI (controls) & 60 & 33 & 27 & $10.2 \pm 1.3$ & $114.4 \pm 13.3$ & $108.4 \pm 11.3$ & $111.5 \pm 10.4$ & - & - \\
\hline NYU (patients) & 143 & 109 & 34 & $11.4 \pm 2.6$ & $106.9 \pm 13.9$ & $103.0 \pm 14.7$ & $105.7 \pm 14.2$ & 49 & 37 \\
\hline NYU (controls) & 105 & 54 & 51 & $12.1 \pm 3.1$ & $112 \pm 13.3$ & $107.5 \pm 15$ & $111 \pm 10.4$ & - & - \\
\hline
\end{tabular}

KKI, Kennedy Krieger Institute; NYU, New York University; VIQ, Verbal Intelligence Quotient; PIQ, Performance Intelligence Quotient; FIQ, Full Scale Intelligence Quotient; $>$ Innattentive, Inattentive group; $>$ Hyp/imp, Hyperactive/impulsive group. 
Table 2: Groups demographics

\begin{tabular}{|c|c|c|c|c|c|c|c|c|c|}
\hline & $\mathrm{N}$ & ô & o & Age (y) & VIQ & PIQ & FSIQ & Clinical Diagnostic & $\mathrm{Mv}$ \\
\hline Total & 335 & 208 & 127 & $11.2 \pm 2.7$ & $110.1 \pm 14.2$ & $105.8 \pm 14.4$ & $\begin{array}{c}108.5 \pm \\
13.8\end{array}$ & - & \\
\hline Combined & 68 & 53 & 15 & $11.46 \pm 2.8$ & $107.2 \pm 15$ & $104.6 \pm 14.5$ & $\begin{array}{c}106.1 \pm \\
13.8\end{array}$ & $78 \% / 22 \% / 0 \%$ & .019 \\
\hline Inattentive & 53 & 34 & 19 & $11.28 \pm 2.7$ & $109.2 \pm 12.3$ & $105.4 \pm 14.9$ & $\begin{array}{c}108.1 \pm \\
13.5\end{array}$ & $62 \% / 38 \% / 0 \%$ & .021 \\
\hline Hyp/imp & 44 & 34 & 10 & $11.36 \pm 2.6$ & $105 \pm 16.1$ & $100.9 \pm 14.9$ & $\begin{array}{c}102.7 \pm \\
15.6\end{array}$ & $82 \% / 11 \% / 7 \%$ & .023 \\
\hline Controls & 170 & 87 & 83 & $11.46 \pm 2.8$ & $112.9 \pm 13.3$ & $107.8 \pm 13.8$ & $\begin{array}{c}111.2 \pm \\
12.9\end{array}$ & $0 \% / 0 \% / 0 \%$ & .022 \\
\hline
\end{tabular}

Hyp/imp, Hyperactive/impulsive, VIQ, Verbal Intelligence Quotient; PIQ, Performance Intelligence Quotient; FSIQ, Full Scale Intelligence Quotient; Clinical Diagnostic Combined (\%) / Innatentive (\%) / Hyperactive/impulsive (\%); Mv, Absolute movement. 
Table 3: Post-hoc statistics (absolute t values, * indicates $\mathrm{p}<0.0042$ )

\begin{tabular}{|c|c|c|c|c|c|c|c|c}
\hline & \multicolumn{3}{|c|}{ Inattentiveness score (light grey) } & \multicolumn{3}{c|}{ Ventral FP connectivity (light grey) } \\
& \multicolumn{3}{|l|}{ Hyperactivity/impulsivity score (dark grey) } & \multicolumn{2}{c}{ Cortico-striatal connectivity (dark grey) } \\
\hline & Combined & Inattentive & Hyp/imp & Controls & Combined & Inattentive & Hyp/imp & Controls \\
\hline Combined & - & $5.171^{*}$ & $5.391^{*}$ & $23.581^{*}$ & - & 1.657 & $3.075^{*}$ & 2.096 \\
\hline Inattentive & $3.058^{*}$ & - & $10.273^{*}$ & $13.359^{*}$ & 1.571 & - & $4.789^{*}$ & $\mathrm{t}<1$ \\
\hline Hyp/imp & 2.236 & $5.204^{*}$ & - & $33.615^{*}$ & $3.969^{*}$ & $4.888^{*}$ & - & $5.460^{*}$ \\
\hline Controls & $25.502^{*}$ & $29.573^{*}$ & $20.613^{*}$ & - & 1.874 & $3.196^{*}$ & 2.05 & - \\
\hline
\end{tabular}


Fig. 1

Click here to download high resolution image

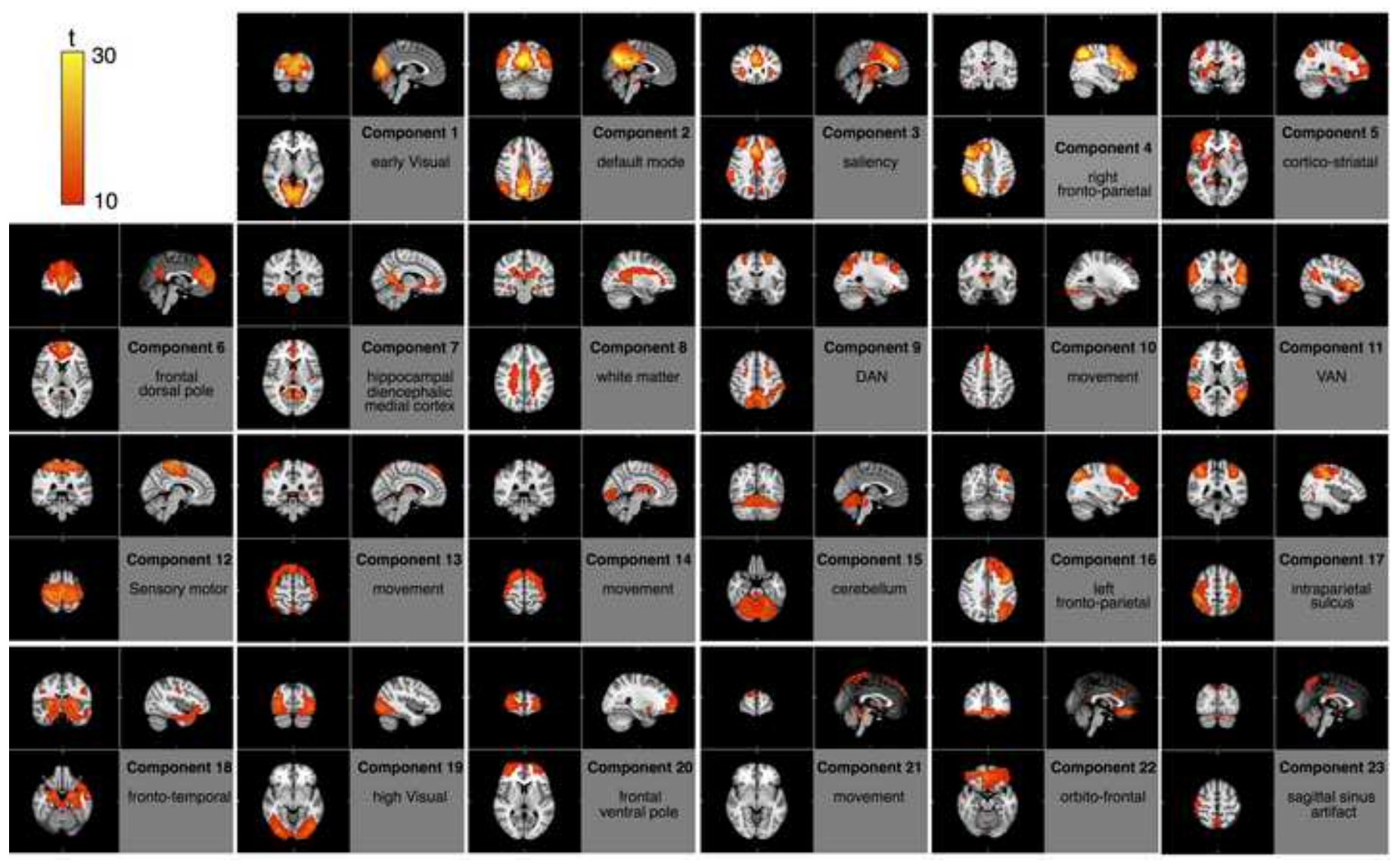


Fig. 2

Click here to download high resolution image

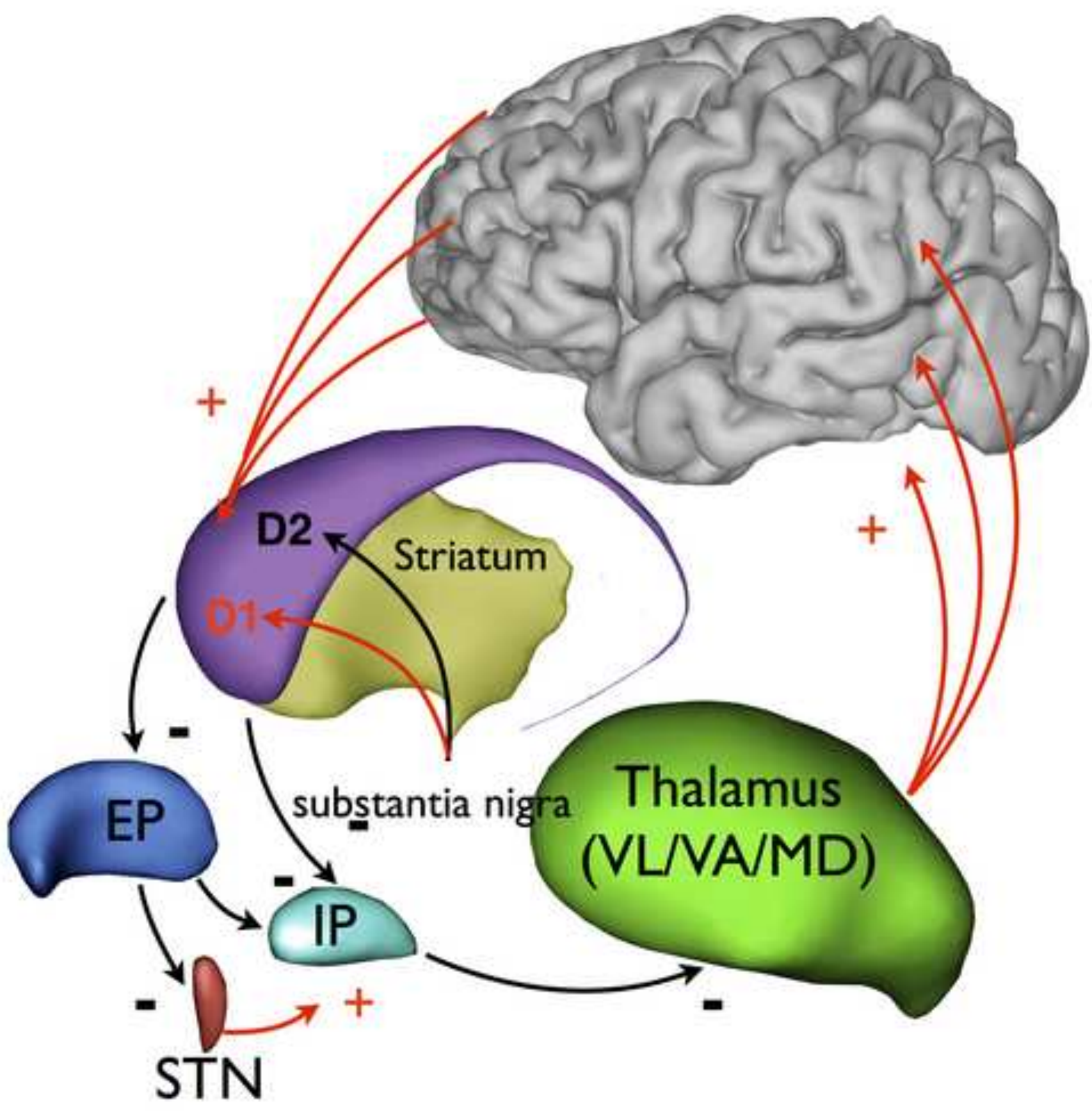

STN, subthalamic nucleus

$\longleftarrow$ excitatory projections

EP, external pallidum

$\longleftarrow$ inhibitory projections

IP, internal pallidum

\&............. projections primarily affected

DI-D2 dopamine receptors type I and 2 


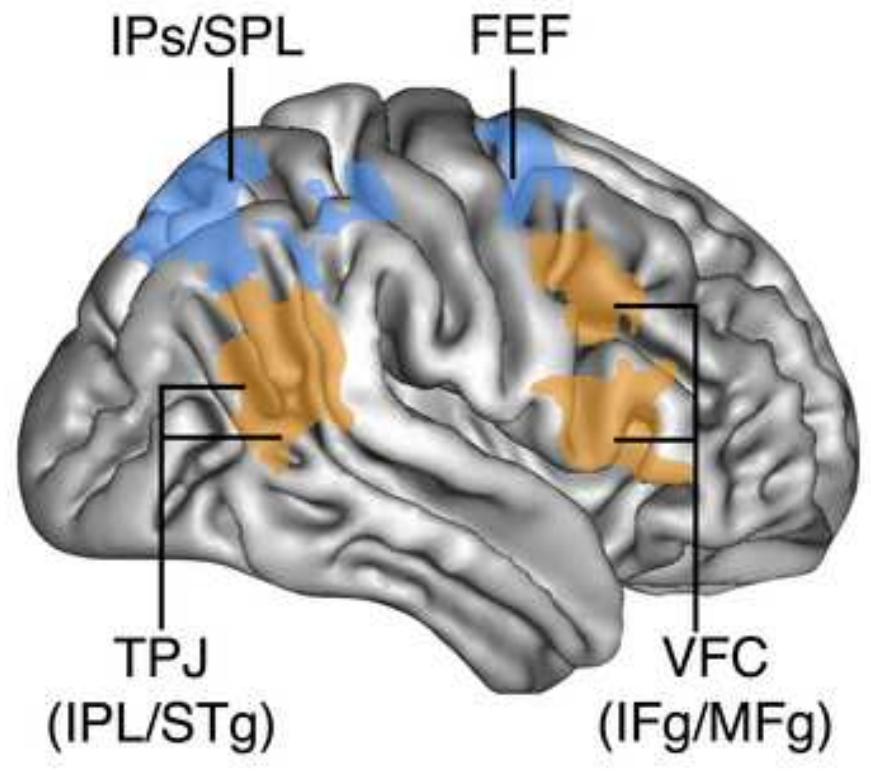

\section{Functional activations}

Controlled goal directed attention: strategic and voluntary orienting of attention towards visual targets

Grabbed stimulus driven attention: Unexpected and automatic orienting of attention towards visual targets 
Fig. 4

Click here to download high resolution image

\section{ADHD groups}

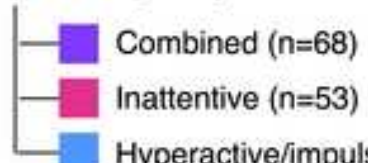

Hyperactive/impulsive $(n=44)$

Controls $(n=170)$

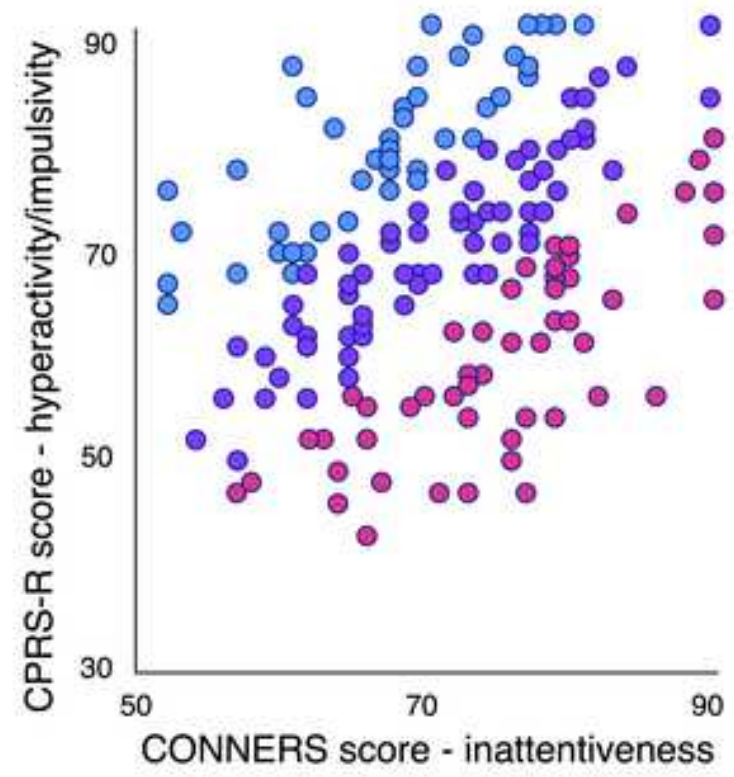

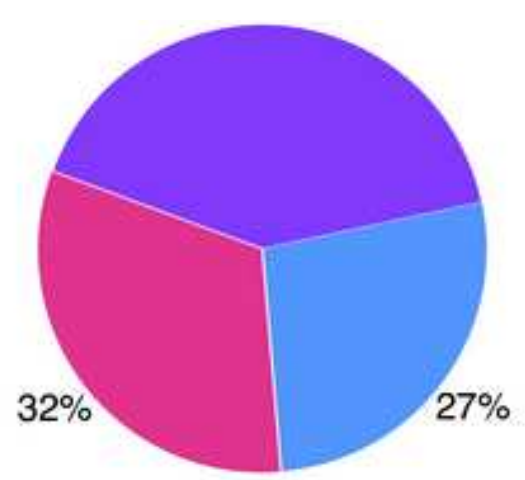

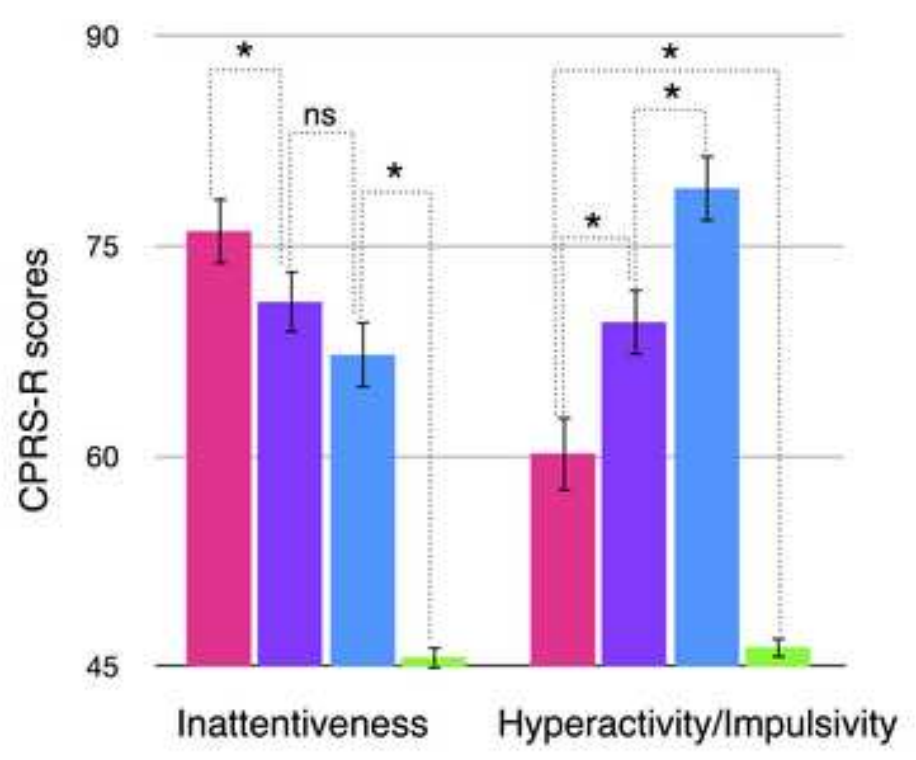


Fig. 5

Click here to download high resolution image
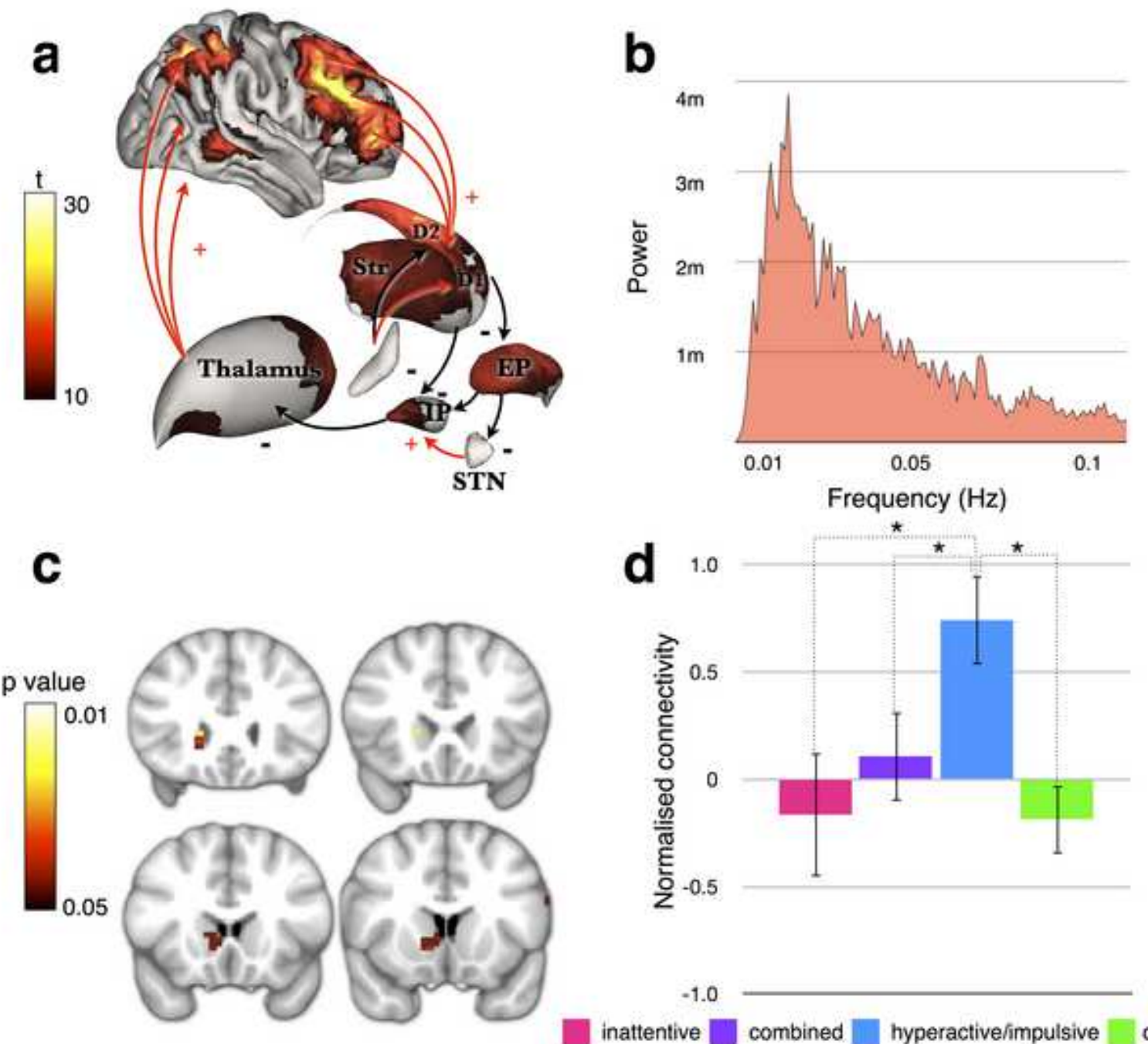

$-1.0$

inattentive combined hyperactive/impulsive controls 
Fig. 6

Click here to download high resolution image

a
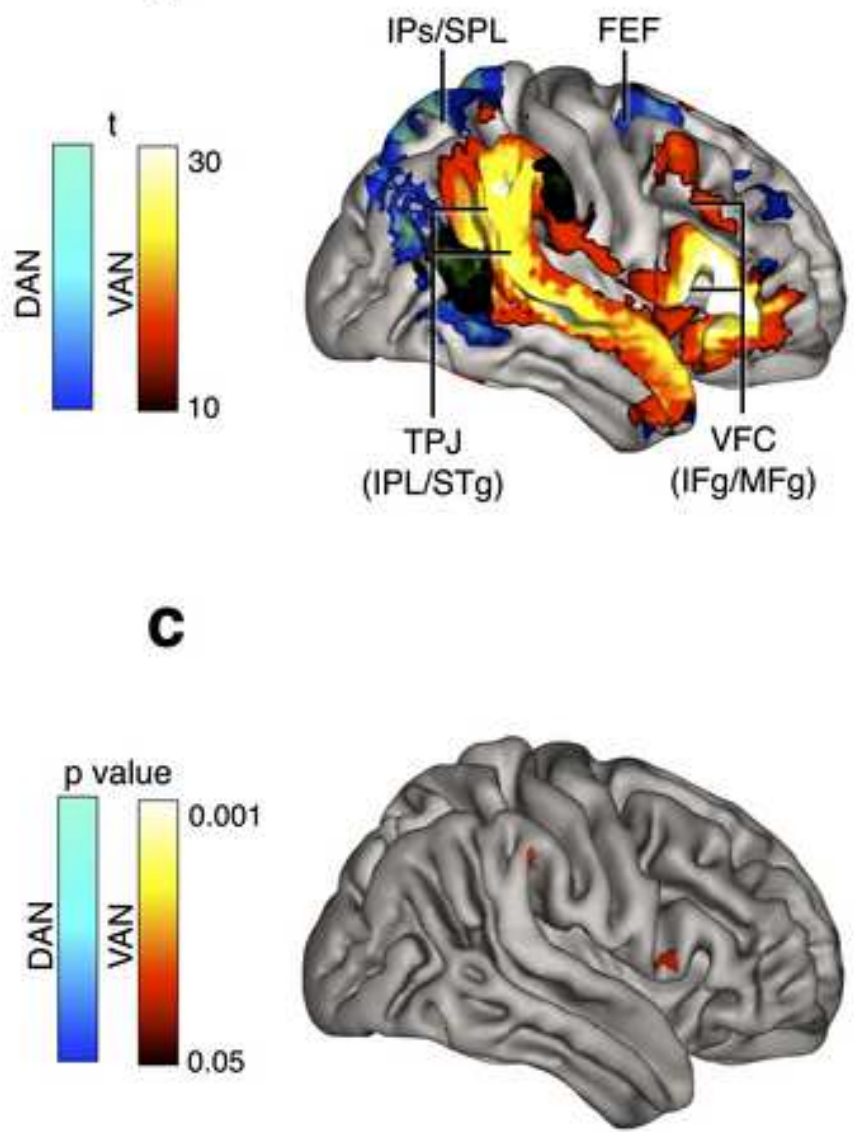

DAN: dorsal attention network VAN: ventral attention network b

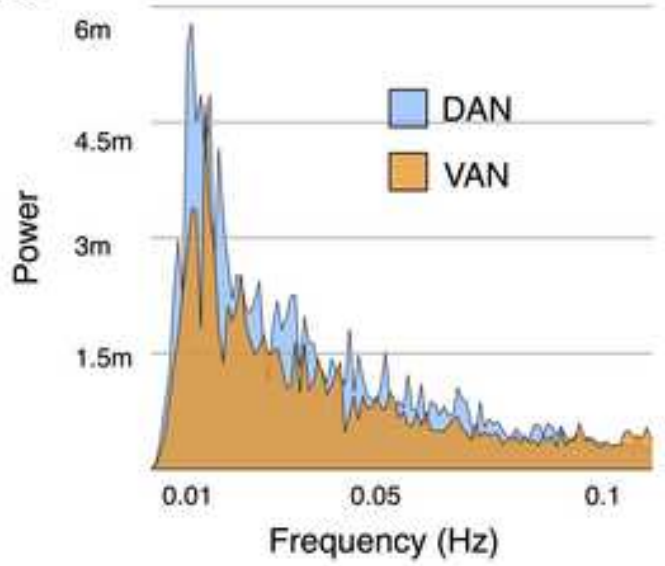

d

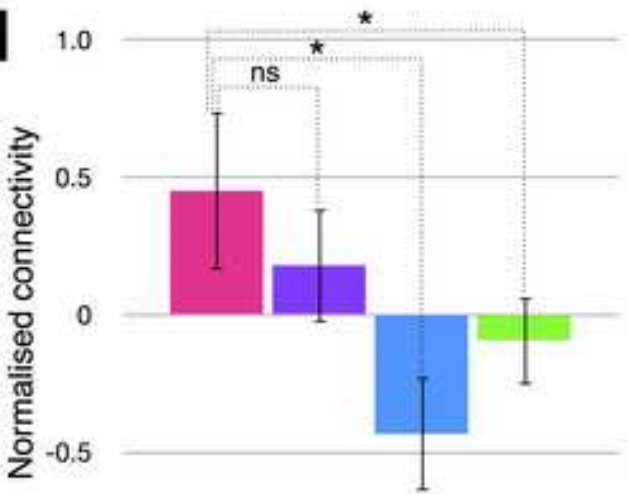

$-1.0$

inattentive combined hyperactive/impulsive controls 
Suppl. material for online publication only

Click here to download Suppl. material for online publication only: Supplementary material_R2.docx 